CASE REPORTS

\title{
Thoracoacromial artery bleeding manifests as an enlarging chest mass: A rare case report
}

\author{
Tsung-Han Lin ${ }^{1}$, Tien-Chi Huang ${ }^{1}$, Wen-Hsien Lee ${ }^{1,2}$, Chun-Yuan Chu ${ }^{1,2}$, Ho-Ming Su ${ }^{1,2}$, Tsung-Hsien Lin ${ }^{1,2}$, Po-Chao \\ $\mathrm{Hsu}^{* 1,2}$ \\ ${ }^{1}$ Division of Cardiology, Department of Internal Medicine, Kaohsiung Medical University Hospital, Kaohsiung Medical University, \\ Kaohsiung, Taiwan \\ ${ }^{2}$ Department of Internal Medicine, Faculty of Medicine, School of Medicine, Kaohsiung Medical University, Kaohsiung, Taiwan
}

Received: November 18, 2018

DOI: $10.5430 /$ crim.v6n3p18
Accepted: July 11, 2019

Online Published: August 15, 2019

\begin{abstract}
Thoracoacromial artery perforation is a rare complication after coronary angiography. Herein, we reported a 70-year-old male previous post coronary artery bypass surgery being admitted for chest discomfort. Coronary angiography from radial artery approach showed all patent bypassed grafts and the patient was sent back to the ordinary ward. However, enlarging mass over left chest wall as woman's breast was noted suddenly and we immediately used sandbag and elastic adhesive tape to compress the mass. Emergent chest computed tomography showed a large hematoma at the left chest wall with active bleeding from pectoral branch of thoracoacromial artery. However, left chest wall mass gradually subsided after compression strategy. This patient reminds physicians thoracoacromial artery perforation manifesting as chest wall mass is a rare but possible complication after coronary angiography.
\end{abstract}

Key Words: Thoracoacromial artery bleeding, Coronary angiography, Complication, Chest mass

\section{INTRODUCTION}

Coronary catheterization is traditionally performed via transfemoral approach because it is easier and safer when arterial cannulation and catheter manipulation. However, transradial approach becomes as effective and possibly safer than transfemoral approach because of less puncture-site complications, including thrombosis, pseudoaneurysm, and hemorrhage. ${ }^{[1]}$ Besides, transradial approach also provides less procedure duration and less dose area product. ${ }^{[2]}$ Nevertheless, the complication of transradial approach still could not be ignored. For example, injury, spasm and painful catheter manipulation, occlusion, or pseudoaneurysm in radial artery. Complex regional pain, minor nerve injury, or arteriovenous fistula have also been reported. ${ }^{[3]}$ The risk of cardiac catheterization and coronary angiography is summarized in Table 1.
Early identification of these complications and immediate management is necessary. Herein we report a rare complication that has never been reported before.

\section{CASE PRESEntation}

A 70-year-old male post coronary artery bypass surgery was admitted for chest discomfort and non-ST elevation myocardial infarction was suspected. Coronary angiography was performed for further examination. Diagnostic catheter included 6Fr JR 4.0, 6Fr JL 3.5, 5Fr Medtronic AL 1.0, and 5Fr Terumo IL 3.5. Due to torturous artery of left brachial artery, Terumo 0.035 " floopy wire was used to go through them. Angiography showed old chronic total occlusion in left main artery and middle right coronary artery, and all patent bypassed grafts including left internal mammillary

\footnotetext{
*Correspondence: Po-Chao Hsu; Email: pochao.hsu@gmail.com; Address: Division of Cardiology, Department of Internal Medicine; Kaohsiung Medical University Hospital, 100 Tzyou 1st Road, Kaohsiung. 80708, Taiwan.
} 
artery to middle left anterior descending artery, saphenous venous graft from aorta to diagonal branch and saphenous venous graft from aorta to distal right coronay artery then to left circumflex artery. After this procedure, the patient was sent back to the intensive care unit. However, an enlarging mass in left chest wall as woman's breast was noted suddenly and progressed rapidly (see Figure 1: Panel A). Although pneumothorax with subcutaneous emphysema should be considered, the patient only had mild chest tightness and denied short of breath. We suspected vascular injury with hematoma during this procedure then immediately used sandbag and elastic adhesive tape to compress the mass and emergent chest computed tomography showed a large hematoma at the left chest wall with contrast extravasation from pectoral branch of thoracoacromial artery (suspect previous wirerelated perforation) (see Figure 1: Panel B, arrow). To prevent the progression of the complication, we also performed follow-up angiography via left transradial approach immediately after computer tomography, which revealed no active bleeding then we did not do any more intervention. We still kept the use of aspirin and ticagrelor until discharge. Fortunately, left chest wall mass gradually subsided after compression strategy for one day. The patient discharged after one week with symmetric chest wall.
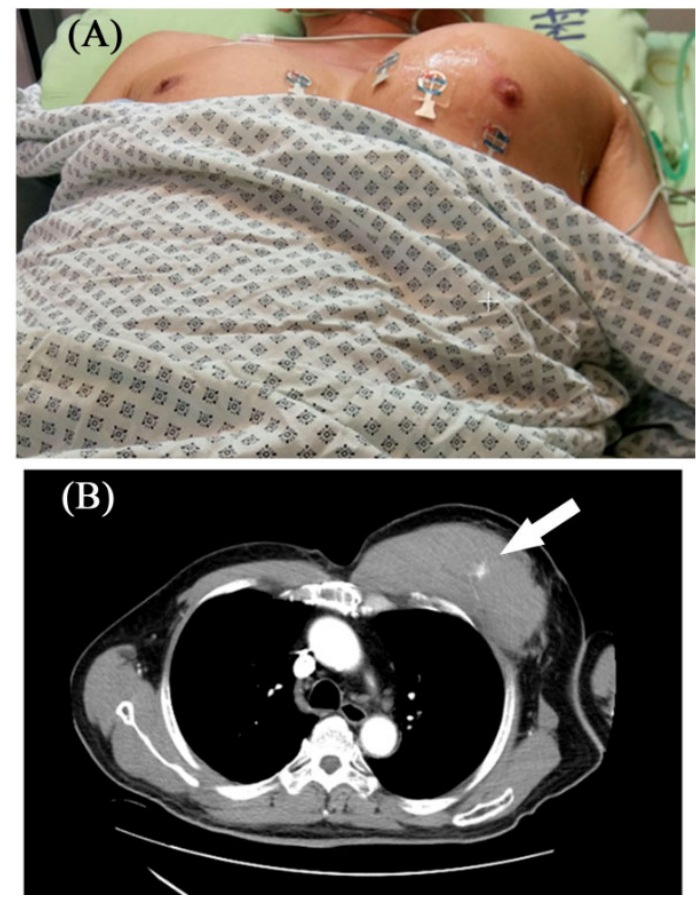

Figure 1. Figure 1A (Upper panel): An enlarging mass in left chest wall as woman's breast was noted suddenly and progressed rapidly. Figure 1B: (Lower panel): Emergent chest computed tomography showed a large hematoma at the left chest wall with contrast extravasation from pectoral branch of thoracoacromial artery.
Table 1. The risk of cardiac catheterization and coronary angiography

\begin{tabular}{lc}
\hline & Percent \\
\hline Mortality & 0.11 \\
Myocardial infarction & 0.05 \\
Cerebrovascular accident & 0.07 \\
Arrhythmia & 0.38 \\
Vascular complications & 0.43 \\
Contrast reaction & 0.37 \\
Hemodynamic complications & 0.26 \\
Perforation of heart chamber & 0.28 \\
Other complications & 0.28 \\
Total of major complications & 1.70 \\
\hline
\end{tabular}

\section{Discussion}

To our knowledge, when we find hematoma after angiography, conservatively noninvasive procedure such as sandbag and elastic adhesive tape to compress the possible bleeding point should be done first. However, if still active bleeding in damaged vessel, we could do low-pressure balloon tamponade, ${ }^{[4]}$ percutaneous stenting with a graft stent, ${ }^{[5]}$ coil embolization of the ruptured vessel if it could be sacrified, ${ }^{[6]}$ or coagulated thrombus injection for artery perforation. ${ }^{[7]}$ Balloon occlusion in the treatment of coronary perforation was widely used in coronary perforation. The methods based on the duration and completeness of the occlusion, including persistent complete occlusion, persistent partial occlusion, intermittent complete occlusion and intermittent partial occlusion. Persistent occlusion may not be sufficiently stable to stop bleeding and protamine could not reach the perforate place to reverse the effect of heparin. Intermittent occlusion may improve tissue tolerability to reperfusion injury and cell death after long-term ischemia, which is known as "ischemic preconditioning (IPC)", and 10 minutes ischemic time is an ideal time. So intermittent occlusion provide a better way for coronary perforation. ${ }^{[8]}$ We reasonably speculate that the procedure could be applied also in peripheral arteries. When balloon occlusion is unsuccessful, endovascular treatment is effective. The use of endovascular treatment of traumatic axillary and subclavian artery injuries was employed after penetrating injury, blunt trauma, iatrogenic catheter-related injury, surgery injury and injuries induced pesudoaneurysm, or arterio-venous fistula. The procedure was successfully in $96.9 \%$ initially and a follow-up patency of $84.4 \%$ after discharge to 70 months. ${ }^{[9]}$ Stent-graft such as VIABAHN could be applied effectively from the femoral route into arteries of upper extremity. ${ }^{[10]}$ The disadvantage was small blood vessel near stent-graft would be jailed and sacrificed. The graft-stents can be expensive and may be limited because the immediately appropriate sized stent-grafts may not be avail- 
able, especially the smaller diameter. Then, coil embolization proximal to the site of perforation, following balloon tamponade, would successful seal the bleeding point. ${ }^{[11]}$ Coagulated thrombus injection for artery perforation may be another novel method. The thrombus comprised by the patient's blood and thrombin could be injected into the perforation site via the tip of a over-the-wire balloon. As previous study, 19 of the 20 perforations (95\%) was successfully treated by this method and only one patient need coil embolization. ${ }^{[7]}$ We should also consider protamine to partially reverse the effect of heparin, and discontinue the possible medication which would lead to coagulopathy, such as antiplatelet agents or anticoagulant. However, in this case, we stopped the bleeding in few hours after using sandbag and elastic adhesive tape to compress the enlarging hematoma, we did not discontinue antiplatelet agents in the next day.

In conclusion, this patient reminds physicians that thoracoacromial artery perforation manifesting as an enlarged chest wall mass is a rare but possible complication after coronary angiography. Immediate chest computed tomography and follow-up angiography should be performed to determine if further intervention should be considered soon. Beyond invasive procedure, noninvasive procedure such as sandbag and elastic adhesive tape to compress the possible bleeding point still play an important role in artery perforation and lower the risk of more severe complication.

\section{CONFLiCTS OF InTEREST Disclosure}

The author declares no conflict of interest

\section{REFERENCES}

[1] Campeau L. Percutaneous radial artery approach for coronary angiography. Cathet Cardiovasc Diagn. 1989;16(1):3-7. PMid:2912567. https://doi.org/10.1002/ccd.1810160103

[2] Brueck M, Bandorski D, Kramer W, et al. A randomized comparison of transradial versus transfemoral approach for coronary angiography and angioplasty. JACC Cardiovasc Interv. 2009;2(11):1047-1054 PMid:19926042. https://doi.org/10.1016/j.jcin.2009.07 .016

[3] Bhat T, Teli S, Bhat H, et al. Access-site complications and their management during transradial cardiac catheterization. Expert Rev Cardiovasc Ther. 2012;10(5):627-634. PMid: 22651838. https: //doi.org/10.1586/erc.12.16

[4] Cooper SG, Sofocleous CT. Percutaneous management of angioplasty-related iliac artery rupture with preservation of luminal patency by prolonged balloon tamponade. $\mathrm{J}$ Vasc Interv Radiol. 1998;9(1 Pt 1):81-83. https://doi.org/10.1016/S1051-0 443(98) 70487-7

[5] Lai CH, Tsai CL, Chang WC, Su CS, Lee WL. Iatrogenic Subclavian Artery Perforation Rescued by Operator-Modified Graft Stent. Yonsei Med J. 2017;58(2):462-466. PMid: 28120581. https : //doi.org/10.3349/ymj.2017.58.2.462

[6] Damodharan K, Bolia A. Transmural coil embolization-alternative technique for management of arterial perforation during subintimal angioplasty. Indian J Radiol Imaging. 2016;26(3):360-363.
PMid:27857463. https://doi.org/10.4103/0971-3026.1904 22

[7] Tokuda T, Hirano K, Yamawaki M, et al. Efficacy and safety of a coagulated thrombus injection for peripheral artery perforation: The coagulated thrombus hemostasis method. Catheter Cardiovasc Interv. 2018;91(2):302-307. PMid:28707386. https://doi .org/10.100 $2 / \operatorname{ccd} .27163$

[8] Wang X, Ge J. Balloon Occlusion Types in the Treatment of Coronary Perforation during Percutaneous Coronary Intervention. Cardiol Res Pract. 2014;2014:784018. PMid: 25506463. https://doi.org/10 $.1155 / 2014 / 784018$

[9] DuBose JJ, Rajani R, Gilani R, et al. Endovascular management of axillo-subclavian arterial injury: a review of published experience. Injury. 2012;43(11):1785-1792. PMid: PMid:22921384. https: //doi.org/10.1016/j.injury.2012.08.028

[10] Abdool MA, Morrison S, Sullivan H. Iatrogenic perforation of subclavian artery as a complication of coronary angiography from the radial route, endovascularly repaired with a covered stent-graft. BMJ case reports. 2013;2013. PMid:23307458. https ://doi.org/10 $.1136 / \mathrm{bcr}-2012-007602$

[11] Damodharan K, Bolia A. Transmural coil embolization-alternative technique for management of arterial perforation during subintimal angioplasty. Indian J Radiol Imaging. 2016;26(3):360-363. PMid:27857463. https://doi.org/10.4103/0971-3026.1904 22 